\title{
A brief history of Social Psychology and its contribution to health in Malawi
}

\section{Chiwoza Bandawe ${ }^{1,2}$}

1.Department of Mental Health, College of Medicine

2.Department of Physchology,University of Cape Town

Social psychology has been defined as "a branch of psychology that is concerned with those aspects of mental life which relate to social interaction and social phenomena in general" ". Hewstone defines it thus: "the scientific study of how personal, situational and societal factors influence the cognition, motivation and behaviour of individuals and (members of) social groups"2. Jahoda lamented that many textbook definitions of social psychology were "pretentious and utterly futile" because they were so "grossly overinclusive that they could encompass a whole range of social and biological disciplines"3. What emerges clearly is that social psychology is seen as having the central task of explaining how the ways in which we think and behave is affected by interaction between people ${ }^{1}$. It is in this context that we define social psychology for the purposes of this article.

\section{Search for relevance}

The history of social psychology has been dogged by crises based on different approaches to understanding human behaviour. A part of this "crisis" has been the "cry" for the field to be more relevant. This need is more pronounced in developing countries. Social psychology is accused of being dominated by issues that are trivial and full of banalities ${ }^{4,5}$. This has been attributed to the field's reliance on few traditional criteria of research such as internal consistency at the expense of other areas such as novelty and pragmatic value $^{5}$. Indeed, many writers have pointed out that the very usefulness and survival of the subject rests on its relevancy and practical application to the target population of study. It has been argued that given the limited resources, social psychology can hardly afford engaging in studies and explanations that do not address concerns and issues in a very real and practically translatable relevant manner. This becomes more pressing in third world countries where issues such as poverty, reduced life expectancy and disease are very much in evidence ${ }^{6}$. Much of the history of social psychology has been considered intellectual self interest at the expense of addressing real needs. Hence with poverty so rampant, issues so pressing, we can hardly afford the luxury of engaging in intellectual debate without addressing real issues. In many ways the standards by which social psychology as a subject shall be evaluated is increasingly moving towards assessing its practical usefulness. What has added to the frustration of the lack of social psychology's contribution to real world issues, is the belief that as a field, social psychology does have something to offer. Its very nature, being the study of individuals and social processes can add immensely to knowledge about real world issues and problems ${ }^{7}$. Given the growing philosophical emphasis on "human development", psychology has a unique opportunity to have an impact ${ }^{8}$.

\section{Social psychology in Africa}

Akin-Ogundeji argued that the history of psychology in Africa is synonymous with the history of colonialism. The colonial era did not do much for the development of psychology with the result that psychology in Africa is not moving in keeping with the changes Africa is going through. He maintains that

"PJsychologists outside academia have little impact, especially in areas of national development like social mobilisation, family planning, youth development, manpower planning, primary health care, rural development, and environmental hygiene and design, where they should be playing major roles" p. $3^{9}$

He argued that psychologists still had to justify the existence of the discipline and was confined to academia. There was the need "to change and refocus psychology in a pulsating society of sporadic social and economic changes" p.3. The empiricist approach to psychology was still largely practiced in Africa. Hence the "essence of psychology which is relating meaningfully to human values, social realities and whole-life issues" (p.4.) has been bypassed by the experimental approach contributing to making psychology in Africa sterile. The result has been that the output of research remains impotent in the face of complex social and economic problems. He spiced his argument with adjectives describing the role of research as being "dry, artificial, irrelevant or meaningless". Some of the research approaches were said to be packaged or imported without direct relevance. There is need to draw on approaches attuned to Africa's social realities and avoid "ivory towerism". The emphasis must lie with the applicability of the research. Psychology must offer explanations of social change.

"Changes are taking place in Africa which demand new thinking, new methods, and new areas of specialisation". He cites social psychology as one area where competencies have been developed but these have made "little or no impact in our societies" (p.4)

In response to this Raubenheimer suggested that academic and professional psychology flourish in South Africa. He showed how psychology flourishes in universities, research, journals, numerous professional associations, that the field enjoys statutory recognition and graduates enjoy large occupational prospects ${ }^{10}$. Foster et al. however pointed out that the existence of apartheid symbolised the most significant difference between South Africa and the rest of Africa. The field of mental health has been racially segregated and facilities for blacks (e.g. mental handicap) were almost non existent. Psychologists, they argued had also played an influential role in developing apartheid ${ }^{11}$.

Carr \& MacLachlan argued that psychology is relevant to developing countries and presented Malawi as a case in point. They pointed to positive changes in teaching (by realigning academic introductory courses towards African experiences), marketing, consultancy and research where psychology was relevant and flourishing within Malawi. Research was targeted towards applied relevance ${ }^{12}$. In response, Ager pointed out that the development of the relevance of the field of psychology should not just be product oriented but needed to take cognisance of the process involved in the development of the field. The search for relevance includes the process of transformation and not just the outcome ${ }^{13}$. 
In line with this Carr \& MacLachlan point out that several commentators seem to have indicated three stages in the progress of psychology in developing countries ${ }^{14}$. These stages were said to be "reminiscent of Henri Tajfell's intergroup account of how social minorities find a "positively distinctive social identity'. The stages are:

Stage One: Attempts to assimilate into the main stream. For example replicating western studies in developing countries. This approach is particularly unhelpful since American psychology is said to be based on norms of local middle class U.S culture ${ }^{8}$.

Stage Two: Emphasis on the positive aspects of cultural attributes although western psychology is the criterion by which this is judged. Hence, psychology is seen through the spectacles of western psychology. Implicit in all this is a "tinge of negative self image" $" 14$.13

Stage Three: Assessment of social reality independent of "apologetics" or comparison with the west. The focus is on effective and relevant psychology that explains and operates within the idiosyncracies of the local environment. Hence this reflects the call for indigenous psychology ${ }^{8}$.

\section{Application of Social Cognitive Theories}

Social cognitive models serve the function of helping us see the dynamics at play in cognitions that influence the interaction with the social world. The theory of Reasoned Action is one such cognitive based theory and deals with the relations among beliefs, attitudes, intentions and behaviours. The theory posits that volitional behaviour, for example, urinating in the lake is predicted by one's intention to perform the behaviour ("I intend to urinate in the lake") ${ }^{15}$. These intentions are determined by normative and subjective factors.

Consequently, the theory of reasoned action is useful in giving direction about health education messages and whether these should be targeted towards normative or personal beliefs. This is a strength of the theory that is invaluable at the practical level. Fishbein argues that many programmes and interventions have been unsuccessful because they misdirect their messages. They may focus on broad issues rather than specifically on attitudes and/or subjective norms that correspond directly with the behaviour one wishes to change. They may also target attitudinal components instead of the relevant normative components and vice versa ${ }^{16}$.The first published study reporting the application of the theory of reasoned action in Malawi was Bandawe \& Foster's 1996 study ${ }^{17}$. In that HIV-related study we assessed intention of 191 students in three secondary schools to engage in sex with the same partner and intention to utilise a condom during each sexual encounter. The findings significantly demonstrated the utility of the theory of reasoned action to the Malawian sample being able to account for $50 \%$ of the variance. For both behaviours intentions were predominantly under attitudinal control. In the second such study of this social cognitive model, Chipwete applied the theory of reasoned action to primary school children in Mangochi, Malawi. This was the first time the theory had been applied to this age group. He compared rural and urban children with regard to intention to abstain from sexual intercourse until marriage, stick to the one same sexual partner and use or have their partners use a condom ${ }^{18}$. His multiple linear regression equations to predict intention were all significant with over $25 \%$ of the variance accounted for in all the behaviours investigated. Chipwete also found that intentions of the primary school children were predominantly under attitudinal control except for intention to stick to one partner, which was predominantly under normative influence. Both these studies ${ }^{17,18}$ demonstrated that the theory of reasoned action can be applied to a Malawian sample and that there are no inherent cultural difficulties with applying this theory to Malawi.

The social cognitive models discussed above are the one level of social psychology and health education. We turn now to examine the other level. Arguing that the application of psychology to problems in Africa is not a luxury, but essential to national development, MacLachlan \& Carr make an attempt to provide a "blueprint, a framework, a conceptual thrust" (p.22). Psychology in Malawi has been described as dynamic and not confined to "mainstream" western post modernism ${ }^{19,20}$. Carr and colleagues ${ }^{21}$ argue that psychology is relevant in developing countries and present a developmental view of social psychology that is neither "historicist" nor "universalist" as the dominant theories are classified. They outline five "discernible modes of social psychology in the Malawian context" ${ }^{20}$,p.178.

The first one is rejuvenation, which refers to the "rejuvenation" of social psychology theories that fell out of vogue. This rejuvenation is due to socio-political changes in the 1990s in Malawi.

The second mode is refutation, which is the refuting of social psychology constructs for example Festinger's cognitive dissonance theory. Under this comes the notion of cognitive tolerance ${ }^{19}$, which asserts that several local studies have demonstrated that most Malawians are comfortable holding two belief systems about a disease without any sense of conflict or contradiction. In other words, Malawians understand the causes of diseases both by western scientific explanations as well as by traditional explanations which draw more on mysticism and the role of spirits and ancestors in the cause of disease $e^{19,21,22}$. They can do so without seeking cognitive "dissonance".

The third mode is realisation, which refers to a realisation of inconsistencies in the guiding philosophy of equity in donor agencies development project delivery. This manifests in the "pay me" situation where recipients of donor aid demand payment for any contribution they make to the programme even if it is said to be in the interests of the local community.

Fourthly, there is the mode of reconstitution. Under this comes the double demotivation theory where, due to the large salary differences between expatriates and locals, both parties in this disparity experienced internal conflicts with equity principles, with the result that the sustainability of the development project is compromised. Another factor is that aid projects which threaten cultural identity may be less sustainable especially since cultural identity always reasserts itself.

Fifthly, there is restatement where the social psychology assumption of the self promoting upward drive, needs to be restated to allow for the costs of individual advancement. The authors have termed this the "pull-down" syndrome, 
where those who are advancing are pulled down by jealous colleagues and relatives to maintain a level of "let us all be poor together".

Carr et al. added another mode which they termed reflection which is concerned with the reflective and evaluative process through which a common principle or thread is seen through all the various events and observations. ${ }^{21}$

Applying this last mode immediately, we can ask what is the common thread that weaves its way through social psychology in Malawi? Carr asserts it is social influence. It cannot be imposed and has to be allowed to happen at its own pace. As Carr puts it "the more one constrains, the less one can sustain" (p.191)

The Malawi psychology literature has reported attempts at testing whether psychological constructs developed in the West, such as the health locus of control measure do have validity in Malawi given the varied cultural, political and economic environment ${ }^{24}$. MacLachlan et al. applied the health locus of control questionnaire (HLOCQ) which assesses subjects' understanding of determinants of health to Malawian university students to assess its cross cultural validity ${ }^{25}$. They investigated malaria, schistosomiasis and AIDS. Their findings did not support the HLOCQ as a valid measure of understanding health risk in the Malawian sample. However using the same sample they applied the Coping Strategy Indicator questionnaire and found close "factorial structure of responses" to the original questionnaire administered in the United States. They attribute the HLOCQ's failure to account for variations in health belief of the Malawian sample to the questionnaire's structure in the composition of its sub-scales ${ }^{26}$.

\section{Potential contributions of social psychology}

There is plenty of scope for social psychology to play a role in Malawi.

The dynamics influencing adopter decisions of successful programmes needs to be understood to ensure effective intervention and message strategies ${ }^{27,28}$. Networks of influence exist to define the socially accepted and preferred behaviours. Identification of such networks and influence processes would therefore be essential and social psychology can play a key role ${ }^{29}$.

Bennet \& Murphy say there is a need for more process evaluation and phased or "episodic" research in order to understand "how" health education messages impact on the target population. There has been too much emphasis on intervention outcome effects (such as behaviour change) with "the assumption that these have resulted directly from the intended intervention. Whilst such outcomes have obvious utility (p.128), they occur without a clear understanding of how the message is received, interpreted and responded to by the target population ${ }^{30}$. This emphasises a "top down" view of behaviour change, which deprives us of understanding the process. There is therefore need for an understanding of how

"Cultural or sub-cultural processes influence the impact of any intervention, and [modify] initiatives accordingly. Such research may also prove a rich testing ground for psychological theory, and may be achieved through the use of both qualitative and quantitative research methods" $($ p.128)

Given the high HIV prevalence in Malawi, it would be worth further exploring the extent to which social control in personal relationships plays a role in shaping health behaviour ${ }^{31}$. The interplay between social support and social control in defining health outcome is beginning to receive more attention, and a study incorporating these dynamics would shed much light on the influence of health related behaviours.

Application of critical psychology theory to health related issues also warrant further investigation. For example, Harré \& van Langenhove expand on "positioning theory" which refers to the analysis of people's interaction in discourse with one another and their relative "positionings" through speech-acts in relation to the story line ${ }^{32}$. Of interest would be to explore how such positionings can advance healthrelated behaviours. What social dynamics operate to position a person into such a place where they are more likely to use a condom during sex for example? What discursive rules exist to allow for the actions that are conducive to health-related behaviours? Since episodes contain thoughts, intentions, plans etc of the individuals involved, they also shape what participants say and $\mathrm{do}^{32}$. There is therefore a need to understand how new episodes or "positions" are negotiated within the idiosyncrasies of the sample under investigation. The objective would then be to align such repositionings with behaviours that are conducive to optimising health from a health education perspective. Social psychology has much scope contribute to health and behaviour in Malawi as reflected in the truth of these words from Desjarlais et al that behaviour "is so rooted in social contexts, so inflected by social differences, and so at the mercy of social resources that behaviours must be thought of as primarily social. They are subject to individual variations at the margins only" (p.229) 33 .

\section{References}

1. McGarty,C., \& Haslam, S.A. (1997). Introduction and a short history of social psychology. In C. McGarty \& S.A. Haslam (Eds.), The Message of Social Psychology (pp. 1-19). Oxford: Blackwell.

2. Hewstone, M. (1997). Three lessons from social psychology: multiple levels of analysis, methodological pluralism, and statistical sophistication. In C. McGarty \& A. Haslam (Eds.) The Message of Social Psychology (pp. 166-181). Oxford: Blackwell.

3. Jahoda, G. (1983). Has social psychology a distinctive contribution to make? In F. Blackler (Ed.), Social Psychology and Developing Countries (pp.21-31). London: John Wiley \& Sons.

4. Fishbein, M. (1997). Predicting, understanding, and changing socially relevant behaviours: Lessons learned. In C. McGarty \& S.A. Haslam (Eds.), The Message of Social Psychology (pp.77-91). Oxford: Blackwell.

5. McGuire, W.J. (1997). Going beyond the banalities of Bubbapsychology: A perspectivist social psychology. In C. McGarty \& S.A. Haslam (Eds.), The Message of Social Psychology (pp. 221-237). Oxford: Blackwell.

6. Omari, I.M. (1983). Some oriental issues in the application of social psychology in Developing Countries. In F. Blackler (Ed.) Social Psychology and Developing Countries (pp.33-43). London: John Wiley 


\section{\& Sons.}

7. Blackler, F. (1983). Preface: The plan of the book. In F. Blackler (Ed.). Social Psychology and Developing Countries (pp.ix-xiv). London: John Wiley \& Sons.

8. Moghaddam, F.M., Bianchi, C., Daniels, K., \& Apter, M.J., \& Harré, R. (1999). Psychology and national development. Psychology and Developing Societies, 11, 121-141.

9. Akin-Ogundeji, O. (1991). Asserting psychology in Africa. The Psychologist: Bulletin of the British Psychological Society, 4, 2-4.

10. Raubenheimer, I. VanW. (1993). Psychology in South Africa. The Psychologist: Bulletin of the British Psychological Society, 6, 169-171.

11. Foster, D., Nicholas, L., \& Dawes, A. (1993). A reply to Raubenheimer. The Psychologist: Bulletin of the British Psychological Society, 6, 172-174.

12. Carr, S. \& MacLachlan, M. (1993). Asserting psychology in Malawi. The Psychologist: Bulletin of the British Psychological Society, 6, 408413.

13. Ager, A. (1993). Psychology and Africa [Letter to the editor]. The Psychologist: Bulletin of the British Psychological Society, 6, 490.

14. Carr, S.C \& MacLachlan, M. (1998). Psychology in Developing Countries: Reassessing its impact. Psychology and Developing Societies, 10, 1-20.

15. Ajzen, I., \& Fishbein, M. (1980). Understanding Attitudes and Predicting Social Behaviour. Englewood Cliffs, N.J: Prentice-Hall.

16. Fishbein, M. (1990). AIDS and behaviour change: An analysis based on the Theory of Reasoned Action. Interamerican Journal of Psychology, 24,37-56.

17. Bandawe, C.R., \& Foster, D. (1996). Aids-related attitudes, beliefs and intentions among Malawian students in three secondary schools. Aids Care, 8, 223-232.

18. Chipwete, J. (1997). Knowledge, beliefs, attitudes, intentions and practices of urban and rural Malawian primary school children to HIV infection. University of Malawi, College of Medicine final year project. Unpublished.

19. MacLachlan, M., \& Carr, S.C. (1994). From dissonance to tolerance: Towards managing health in tropical countries. Psychology and Developing Societies, 6, 119-129.

20. Carr, S.C. (1996). Social psychology in Malawi: Historical or Developmental? Psychology and Developing Societies, 8, 177-197.

21. Carr, S.C., McAuliffe, E., \& MacLachlan, M. (1998). Psychology of Aid. London: Routledge.

22. Shaba, B., MacLachlan, M., Carr, S.C., \& Ager, A. (1993). Palliative versus curative beliefs regarding tropical epilepsy as a function of traditional and medical attributions. The Central African Journal of Medicine, 39, 165-167.

23. Ager, A., Carr, S., MacLachlan, M., \& Kaneka-Chilongo, B. (1996). Perceptions of tropical health risks in Mponda, Malawi: Attributions of cause, suggested means of risk reduction and preferred treatment. Psychology and Health, 12, 23-31.

24. MacLachlan, M. (1998). Health and welfare in Malawi. In M. MacLachlan \& S.C Carr (Eds.) Perspectives in Malawian Psychology: A Reader for Students (pp.75-95.). Dublin-Zomba-Darwin: Zikomo Press.

25. MacLachlan, M., Ager, A., \& Brown, J. (1996). Health locus of control in Malawi: A failure to support the cross-cultural validity of the HLOCQ. Psychology and Health, 12, 33-38.

26. Ager, A., \& McLachlan, M. (1998). Psychometric properties of the Coping Strategies Indicator (CSI) in a study of coping behaviour amongst Malawian students. Psychology and Health, 13, 399-409.

27. Gingiss, P.L., Gottlieb, N.H., \& Brink, S.G. (1994). Measuring cognitive characteristics associated with adoption and implementation of health innovations in schools. American Journal of Health Promotion, 8, 294-301.

28. McCormick, L.K., Steckler, A.B., \& McLeroy, K. (1995). Diffusion of innovations in schools: A study of adoption and implementation of school-based tobacco prevention curricula. American Journal of Health Promotion, 9, 210-219.

29. Mbere, N. (1981b). Applied community participation in sanitation provision. Sanitation in Developing Countries. Proceedings of a workshop on training held in Lobotse, Botswana, 14-20 September, 1980 (pp.118-122). Ottawa: International Development Research Centre.

30. Bennet, P \& Murphy, S. (1994). Psychology and health promotion. The Psychologist: Bulletin of the British Psychological Society, 7, 126128.

31. Lewis, M.A., \& Rook, K.S. (1999). Social control in personal relationships: Impact on health behaviors and psychological distress. Health Psychology, 18, 63 - 71.

32. Harré, R. \& Van Langenhove, L. (1999). Positioning Theory. Oxford: Blackwell.

33. Desjarlais, R., Eisenberg, L., Good, B., \& Kleinman, A. (1995). World Mental Health: Problems and Priorities in Low-Income Countries. New York: Oxford University Press. 